NASA Technical Memorandum 87314

\title{
Space Station 20-kHz Power Management and Distribution System
}

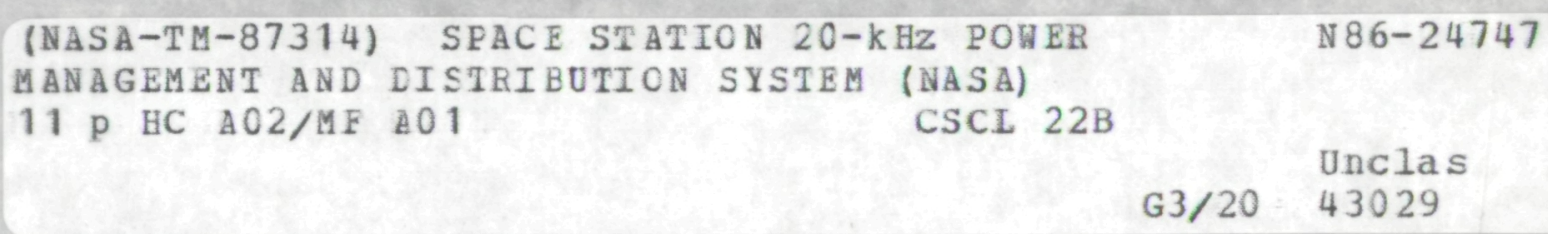

Irving G. Hansen and Gale R. Sundberg

Lewis Research Center

Cleveland, Ohio

Prepared for the 1986 Power Electronics Specialists Conference sponsored by the Institute of Electrical and Electronics Engineers Vancouver, Canada, June 23-27, 1986

\section{N/SA}

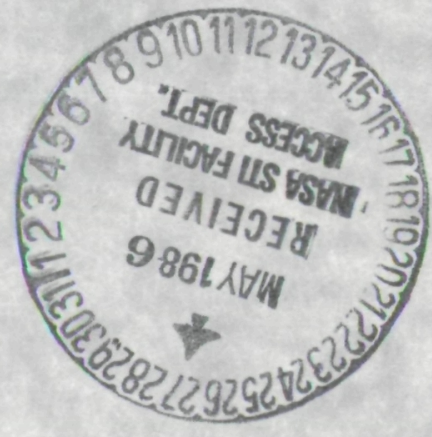


SPACE STATION 20-kHz POWER MANAGEMENT AND DISTRIBUTION SYSTEM

Irving G. Hansen and Gale R. Sundberg

National Aeronautics and Space Administration

Lewis Research Center

Cleveland, Ohio 44135

ABSTRACT

During the conceptual design phase a $20-\mathrm{kHz}$ power distribution system was selected as the reference for the space station. The system is single-phase 400 VRMS, with a sinusoidal wave form. The initial user power level will be $75 \mathrm{~kW}$ with growth to $300 \mathrm{~kW}$. The high-frequency system selection was based upon considerations of efficiency, weight, safety, ease of control, interface with computers, and ease of paralleling for growth. Each of these aspects will be discussed as well as the associated trade-offs involved. An advanced development program has been instituted to accelerate the maturation of the highfrequency system. Some technical aspects of the advanced development program will be discussed.

\section{BACKGROUND}

The National Aeronautics and Space Administration is developing a manned space station to be operable in the mid-nineties. The power system for the space station must initially supply a power level of $75 \mathrm{~kW}$, and allow for eventual growth to $300 \mathrm{~kW}$. Figure 1 is an outline of the space station as currently conceived. The power management and distribution (PMAD) system must accept energy from the photovoltaic solar arrays and the solar dynamic generators and deliver controlled power to numerous dispersed loads. During eclipse periods power is supplied by the energy storage systems.

One significant system driver appeared early in the study - cost. The cost of electrical power generated by the space station will be enormous: $>500$ dollars $/ \mathrm{kWh}$. This cost permeates all aspects of the power system, and precludes many conventional approaches. Therefore, great care must be exercised when adapting existing relatively inefficient PMAD technology.

During the conceptual design phase of this program a unique power system was used as the reference for comparison. As presently developed, the system delivers 440 VRMS, $20 \mathrm{kHz}$, single-phase

ower, using a sinusoidal waveform. To data this high-frequency power system has demonstrated marked technical advantages in efficiency, low parts count, low system mass, safety, ease of control, simple interfaces with load management computers, and ease of paralleling the many modules for growth.

\section{AC SYSTEM CONCEPTS}

As presently configured the system delivers regulated $440 \mathrm{~V}, 20 \mathrm{kHz}$, single-phase sinusoidal ac power. The justification for the selection of an electrical PMAD system with these characteristics is given below. A distribution voltage of 440 VRMS represents the near term capabilities of directly coupled high-frequency solid-state power devices. Even though developments of high voltage switching components are ongoing, present efforts seem to be centered near the $500 \mathrm{~V}$ range. These solid-state switching devices are to be operated directly off line in remote power controllers, and in voltage/frequency controlled synthesizers to allow variable speed ac motor operation. In the case of motor operation, 440 RMS single-phase power will allow direct off line synthes is of 3 phase, $115 / 208 \mathrm{~V}$ ac power with a voltage over range of 10 percent. The $20 \mathrm{kHz}$ operating frequency allows a good balance between power rating per module, audio noise considerations, and component sizing. A line regulation of +2.5 percent at the user interface will, for a large class of user loads, not require any further regulation. Making additional voltage regulation unnecessary will in turn avoid additional energy loss, and reduce the end to end system part count.

\section{COMPONENT SIZING}

In the case of magnetic components, however, size reduction is not a linear function of increasing frequency. As an example the relative mass of a $25 \mathrm{~kW} 20 \mathrm{kHz}$ transformer relative to an equivalent $400 \mathrm{~Hz}$ transformer is only about $8 / 1$ notwithstanding the $50 / 1$ reduction in operating frequency. The difference in scale results from necessary substitutions of magnetic materials, and reduction of flux levels at high frequency. Furthermore a $20 \mathrm{kHz}$ transformer would have all linear dimensions reduced by about a factor of two, and all heat conducting surfaces reduced by a factor of about four. In the case of multikilowatt transformers this reduction of surface will necessitate improved heat transfer techniques $(1,2,3)$. 


\section{SINGLE-PHASE DISTRIBUTION}

From a user point of view the single-phase high-frequency system provides essentially constant power. However, and perhaps more importantly, system status sensing, reconfiguration, and subsequent status verification is simplified. For a single-phase system the total numbers of conductors, contactors, controls, and sensors are reduced by a factor of three as compared to a three-phase system.

\section{MODULE SIZING}

Generally in any electronic power converter the maximum permissible operating voltage is limited by the semiconductor ratings. Once the semiconductor voltage limit is reached, further increases in power must then be met by increasing the current. In the case of a resonant converter an increase in energy transfer at fixed maximum voltage requires a reduction in the tank characteristic impedance. For example; typically a $10 \mathrm{~kW}$ converter operating at $20 \mathrm{kHz}$ would require a capacitor of about $1 \mu \mathrm{F}$, and a resonant inductance of only about $10 \mu \mathrm{H}$.

As the inherent circuit parasitic inductance of a $10 \mathrm{~kW}$ converter will become noticeable when dealing with resonant inductances of a few microheneries, the result is a form of eventual frequency-power product limit for any given circuit layout. Based upon several hardware builds, experience would indicate that single-stage power levels of 20 to $30 \mathrm{~kW}$, and high efficiencies (96 to 97 percent) are very realistic goals at $20 \mathrm{kHz}$ (4-6). It should be noted that a resonant converter with its sinusoidal current (minimum di/dt) will operate at a higher frequency-power product than an equivalent nonsinusoidal converter.

\section{EMI/RFI AUDIO SUSCEPTIBILITY}

The use of a low inductance transmission line (which is required due to other system constraints) insures that little magnetic field extends "outside" the cable, since the implied close proximity of the conductors cancels the electric field (similar to the case of a co-ax cable). The EMI isolation taken together with the fact that the wave form is a single high-frequency sinusoid results in an inherently clean system. As an alternate example consider the of ten encountered square wave power waveform that generates an extremely wide noise spectrum.

\section{SYSTEM SAFETY}

While no data seems to be available which deals directly with $20 \mathrm{kHz}$ power, observations may be drawn from tests performed at dc, $60 \mathrm{~Hz}, 10$ $\mathrm{kHz}$, and under one cycle pulse conditions (10). These tests indicate that the "let-go-potential" at $20 \mathrm{kHz}$ is significantly higher than at either $60 \mathrm{~Hz}$ or $400 \mathrm{~Hz}$. In addition systems which operate at lower frequency, or at dc would require extensive modification in order to match the energy limited characteristics inherent in the resonant converter. As an example the maximum energy in a $75 \mathrm{~kW}$ resonant power system is less than $2 \mathrm{~J}$.

\section{SOURCE CONVERSION}

One central concept of the high-frequency distribution system is the application of the parallel resonant (Mapham) converter as shown in Fig. 2 (7). This particular resonant configuration provides the necessary low output impedance, and due to the sinusoidal nature of the resonant current, experiences very little turn off losses in the semiconductor switches. The resonant turn off concept is shown in Fig. 3 . In this illustration the resonant frequency is higher than the triggered system frequency. This condition allows resonant turn off, and provides a dead time between half cycles for housekeeping and status updates. The resonant capacitor integrates the current into a relatively low distortion ( $>5$ percent THD) voltage source. Also to be noted on Fig. 3 is the inherent symmetry of the bridge topology. This symmetry is also shown in Fig. 4, which has been redrawn to illustrate the highfrequency port's parallel capacitance, and the low-frequency port with series inductance. It is this symmetry of the full bridge resonant converter that allows controlled bi-directional four quadrant power flow. Functionally the converter performs a modulation/demodulation function (Fig. 5). When modulating power from a lowfrequency source, the low frequency (input) establishes the modulation envelope. In the frequency domain the resulting modulation would be classified as double sideband suppressed carrier (DSSC).

Not shown for simplicity, is the presence of a low pass input filter which decouples the source. As in any switching converter, the input filter capacitor supplies the high-frequency current to the converter. A significant advantage is this switching converter, however, is the relatively low operating frequency in the filter capacitor due to the sinusoidal current. Also notable is the fact that during modulation the input current remains a continuous undistorted analog of the voltage. This is very important when dealing with a source unable to supply reactive power.

\section{SOURCE REGULATION}

A phasor regulation scheme is shown in Figs. 8 and 9. In this configuration synchronized, but phase delayed, multiple converters have their outputs added as phasors. The amplitude of the single-phase resultant is controlled by time delaying the common clock pulse. For three phase ac input power a similar configuration isolates each low-frequency input phase with a dedicated converter. The resulting amplitude modulation (Fig. 5) will be cancelled when series summation is performed. In this configuration each phase of the low frequency input undergoes continuous and linear loading. Finally a combination of phasor regulation (bi-phase) and, modulation envelope cancellation is shown in Fig. 9. Each 
Irving G. Hansen and Gale R. Sundberg

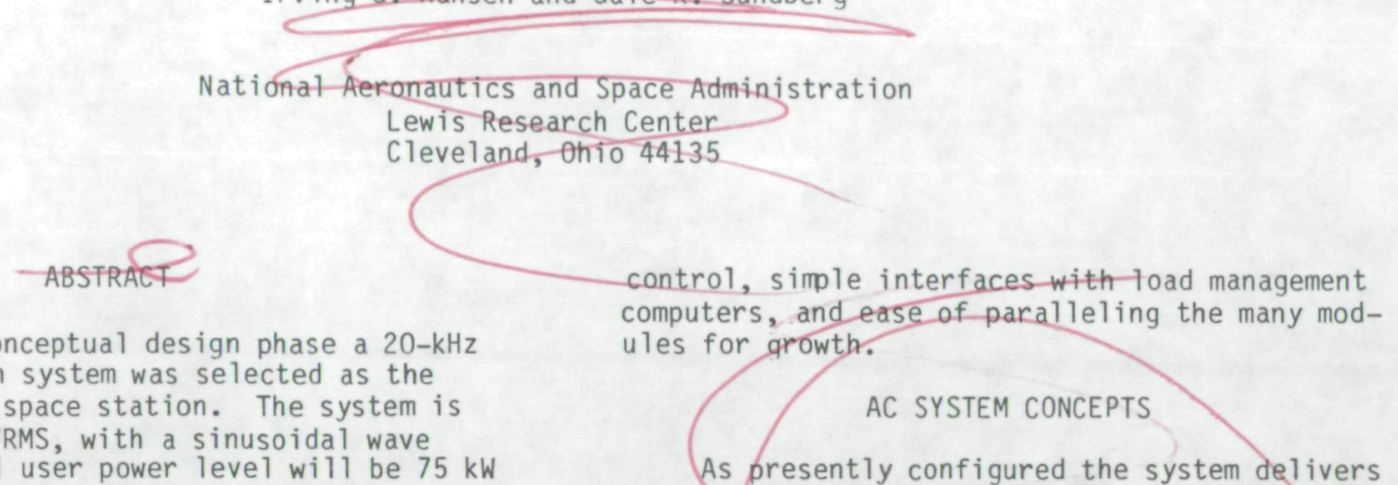

As presently configured the system delivers regulated $440 \mathrm{~V}, 20 \mathrm{kHz}$, single-phase sinusoidal ac power. The justification for the selection of an electrical PMAD system with these characteristics is given below. A distribution voltage of 440 VRMS represents the near term capabilities of directly coupled high-frequency solid-state power devices. Even though developments of high voltage switching components are ongoing, present efforts seem to be centered near the 500 y range. These solid-state switching devices are to be operated directly off line in remote power controllers, and in voltage/frequency controlled synthesizers to allow variable speed ac motor operation. In the case of motor operation, 440 RMS single-phase power will allow direct off line synthesis of 3 phase, $115 / 208 \mathrm{~V}$ ae power with a voltage over range of 10 percent. The $20 \mathrm{kHz}$ operating frequency allows a good balance between power rating per module, audio noise considerations, and component sizing. A line regulation of +2.5 percent at the user interface will, for a large class of user loads, not require any further regulation. Making additional voltage regulation unnecessary will in turn avoid additional energy loss, and reduce the end to end system part count.

\section{COMPONENT SIZING}

One significant system driver appeared early in the study - cost. The cost of electrical power generated by the space station witl be enormous: $>500$ dollars $/ \mathrm{kWh}$. This cost permeates all aspects of the power system, and precludes many conventional approaches. Therefore, great care must be exercised when adapting existing relatively inefficient PMAD technology.

During the conceptual design phase of this program a unique power system was used as the reference for comparison. As present1y developed, the system delivers 440 VRMS, $20 \mathrm{kHz}$, single-phase

ower, using a sinusoidal waveform. To data this high-frequency power system has demonstrated marked technical advantages in efficiency, low parts count, low system mass, safety, ease of

In the case of magnetic components, however, size reduction is not a linear function of increasing frequency. As an example the relative mass of a $25 \mathrm{~kW} 20 \mathrm{kHz}$ transformer relative to an equivalent $400 \mathrm{~Hz}$ transformer is only about $8 / 1$ notwithstanding the $50 / 1$ reduction in operating frequency. The difference in scale results from necessary substitutions of magnetic materials, and reduction of flux levels at high frequency. Furthermore a $20 \mathrm{kHz}$ transformer would have 11 linear dimensions reduced by about a factor of two, and ald heat conducting surfaces reduced by a factor of about four. In the case of multikilowatt transformers this reduction of surface will necessitate improved heat transfer techniques $(1,2,3)$. 
of the described configurations has been verified by actual full power system tests. The test results together with schematics, waveforms, efficiency measurements, and system stability measurements are contained in Refs. 4, 6, and 8 .

\section{LOAD CONVERSION}

When functioning as a demodulator the lowfrequency output is synthesized by high frequency half sine pulses. The resulting modulation (pulse population) has its voltage controlled by the pulse density, and its frequency controlled by the pulse polarity pattern. This in turn allows the output frequency to be controlled independently of the output voltage. This particular capability has very important implications for variable speed motor operation as it allows independent control of both the speed, and the torque. It also simplifies bi-directional control of ac power (8).

Finally on Fig. 4, the resonant circuit has been redrawn as an equivalent low pass L.C. filter with the output taken across the capacitor. Parallel operation of such converters when commonly clocked is inherently stable. Operation under such conditions becomes the equivalent of summing synchronized, in phase, current sources (inductors) into a common current sink (paralleled capacitors). Under these conditions each converter will supply current to the common capacitor load independently of the other converters. Normally no further current balance is needed. If the energy flow, however, from a particular source is to be altered, as for example to balance a battery, the current supplied by any particular converter may be controlled by adjusting its computer controlled voltage reference. Additional converters, additional distribution networks, or additional loads may be accommodated without disturbing this inherent load sharing.

The ease with which synchronized converters may be paralleled is illustrated in Fig. 5 . In a laboratory demonstration in which two 10-kW converters were synchronized from a common clock. Step paralleling was accomplished by a mechanical switch. The oscillographs illustrate the characteristically stable load sharing.

\section{END-TO-END CONSIDERATIONS}

An important concept of the high-frequency power system concerns the minimization of the conversion steps between the energy source and the using load. Each conversion of energy adds complexity, weight, waveform distortion, and increased losses. Any end-to-end power system design must early address the problem of containing all of the effects of a large number of power conversions. Examination of a so-called dc/dc converter (Fig. 7) will quickly show that in fact several conversions are employed; a dc/ac conversion, a dc isolation transformer, and a $\mathrm{ac} / \mathrm{dc}$ conversion. Another equivalent converter is also shown in Fig. 7. In this configuration the dc/ac converter is split in two. The dc/ac portion now serves as an ac source driving the transmission line. The ac/dc portion of the process is now free to become specifically dedicated to the requirements of a particular load. In such a system the number of conversion steps is required to provide isolated regulated power minimal, and the accommodations of a users particular needs may be optimized. The various interface details and demands are easily controlled with a few standardized circuits (8).

\section{POWER FEEDER DESIGN}

At high audio frequencies a power cable becomes sensitive to skin effects and the attendant increase in effective resistance. The use of standard wiring techniques (Litz) and low inductance cable geometries limit distribution losses to less than 2 percent and the total feeder drop both inductive and resistive to less than 3 percent. These low values of feeder voltage drops limit crosstalk effects, and enable a regulated "utility system" concept. The present developed $25 \mathrm{~kW}$ cable has the following measured parameters: $R=0.83 \mu \Omega / \mathrm{m} ; L=0.035 \mu \mathrm{H} / \mathrm{m} ; C=0.0014 \mu \mathrm{f} / \mathrm{m}$.

\section{STATION POWER SYSTEM}

The space station power system is configured as a split system. The low-frequency ports in the source converters will accept energy as either dc in the case of a photovoltaic source, or lowfrequency ac as in the case of a solar dynamic source. All source converters have their regulated outputs paralleled onto a common singlephase distribution bus. Those converters which are configured to be bi-directional will also pass energy from their high-frequency port to their low-frequency port. This latter capability may be required for start up sequences, and during failure correction, or shuttle docking exercises. Each load converter accepts energy at its highfrequency port and delivers either ac, dc, or some required combination at its low-frequency port. With this configuration, a true utility concept is formed in that all sources and all loads are in parallel sharing a common feeder line. As in a utility this distribution concept allows the ac voltage to be adjusted to local requirements by means of transformers. On the space station for example, areas subject to depressurization could have local supply voltages reduced to prevent electrical breakdown. With a $20 \mathrm{kHz}$ distribution frequency the single-phase isolation transformers required will have a relatively small mass impact, typically in the range of $0.2 \mathrm{~kg} / \mathrm{kW}$. These transformers also provide another significant advantage to the system, since their inclusion in the system will restore the common mode isolation required for single-point grounding, and allow the use of ground fault interrupters.

\section{STATION DISTRIBUTION LENGTHS}

Long distribution lengths are often cited as a potential problem, it should be assessed however in the actual application. A voltage fed power distribution system must have low source and transmission impedances relative to the load impedance to achieve efficient energy transfer. In any system, the resultant impedance mismatch 
will cause reflections of energy from the load back to the source. For $20 \mathrm{kHz}$ transmission lines $300 \mathrm{ft}$ long the reflection is only about $4^{\circ}$ delayed from the incident wave and causes no problems. The relative long wave length at $20 \mathrm{kHz}$ $(15 \mathrm{~km})$ compared to the physical length of the space station power feeder $(100 \mathrm{~m})$ precludes any significant effect due to reflected energy.

\section{PRESENT STATUS}

A $25 \mathrm{~kW}$ system has been assembled and tested. This system will accept either ac or dc energy, transmit $25 \mathrm{~kW}$ of $20 \mathrm{kHz}$ energy over a $100 \mathrm{~m}$ line at 440 VRMS, and convert the energy into variable ac or dc power. All output waveforms, voltage levels, and energy flows are under the cycle-bycycle control of a central computer (6).

For the space station power system application a $75 \mathrm{~kW}$ photovoltaic power system was evaluated on an end-to-end basis. The RCA price codes, and actual existing hardware characteristics were utilized. The resulting cost estimates were compared to these obtained using existing characteristics of conventional $400 \mathrm{~Hz}$ equipment. This costing exercise indicated an acquisition cost savings of 100 million dollars, and a life cycle cost savings of 500 million dollars for the space station.

\section{AIRCRAFT IMPLICATIONS}

To illustrate the advantages of highfrequency distribution, the secondary power system of a Boeing 767 was redesigned with the cooperation of the Boeing Aircraft Company. The aircraft secondary power system was configured as an "all electric" airplane using the $20 \mathrm{kHz}$ system as described. Computer "flights" were made on aircraft using both the original and the modified secondary power system. The results of the study showed both a weight savings, and a fuel savings of about 10 percent each (9).

\section{FUTURE APPLICATIONS}

The power technology division of NASA Lewis considers the high-frequency power system to be a prime candidate for a large number of potential and ongoing power system studies. Among these potential applications are; Shuttle II, Transatmospheric Vehicles, SP 100 (both thermal electric and Stirling engine), and Spacecraft 2000. For each of these applications, the versatility of the high-frequency power system represents an enabling technology allowing a large number of mass-limited missions for new generations of aero-spacecraft, many versitile power system configurations, and accommodation of all conceivable user load interface requirements.

\section{CONCLUSIONS}

The $20-\mathrm{kHz}$ power system has been brought to a mature state of development, component, and circuit design concepts are supported by a decade of development aimed directly at aerospace applications. The high demonstrated efficiency, low mass, and versitility of this power management concept allows the assemblage of large complex systems, retains full end-to-end control, and is easily adaptable to a wide range of users needs.

\section{REFERENCES}

1. I. Hansen, Description of a $2.3 \mathrm{~kW}$ power transformer for space applications, "r NASA TM-79138, 1979.

2. I.G. Hansen and M. Chester, "Heat pipe cooling of power processing magnetics," AIAA Paper 79-2082, 0ct. 1979.

3. J.P. Welsh, "Design and development of multi kilowatt power electronic transformer," NASA CR-168082, 1983.

4. J. Mildice and L. Waapes, "Resonant ac Power system proof-of-concept," NASA CR-175069, 1986.

5. R. Robson and D. Hancock, "10 kW series resonant converter design, transistor characterization, and base-drive optimization," NASA CR-165546, 1981.

6. J. Mildice, "Ac power system test bed," NASA CR-175068, 1986.

7. N. Mapham, "An SCR inverter with good regulation and sine-wave output," IEEE Trans. Ind. Gen. Appl., vol. IGA-3, pp. 176-187, 1967.

8. J. Mildice, "Bi-directional power converter control electronics," NASA CR-175070, 1986.

9. A.C. Hoffman, I.G. Hansen, R.F. Beach, R.M. Plencner, R.P. Dengler, K.S. Jefferies, and R.J. Frye, "Advanced secondary power system for transport aircraft," NASA TP-2463, 1985.

10. Accident Prevention Manual for Industrial Operations, 6th Edition, Chicago: National Safety Council, 1969. 


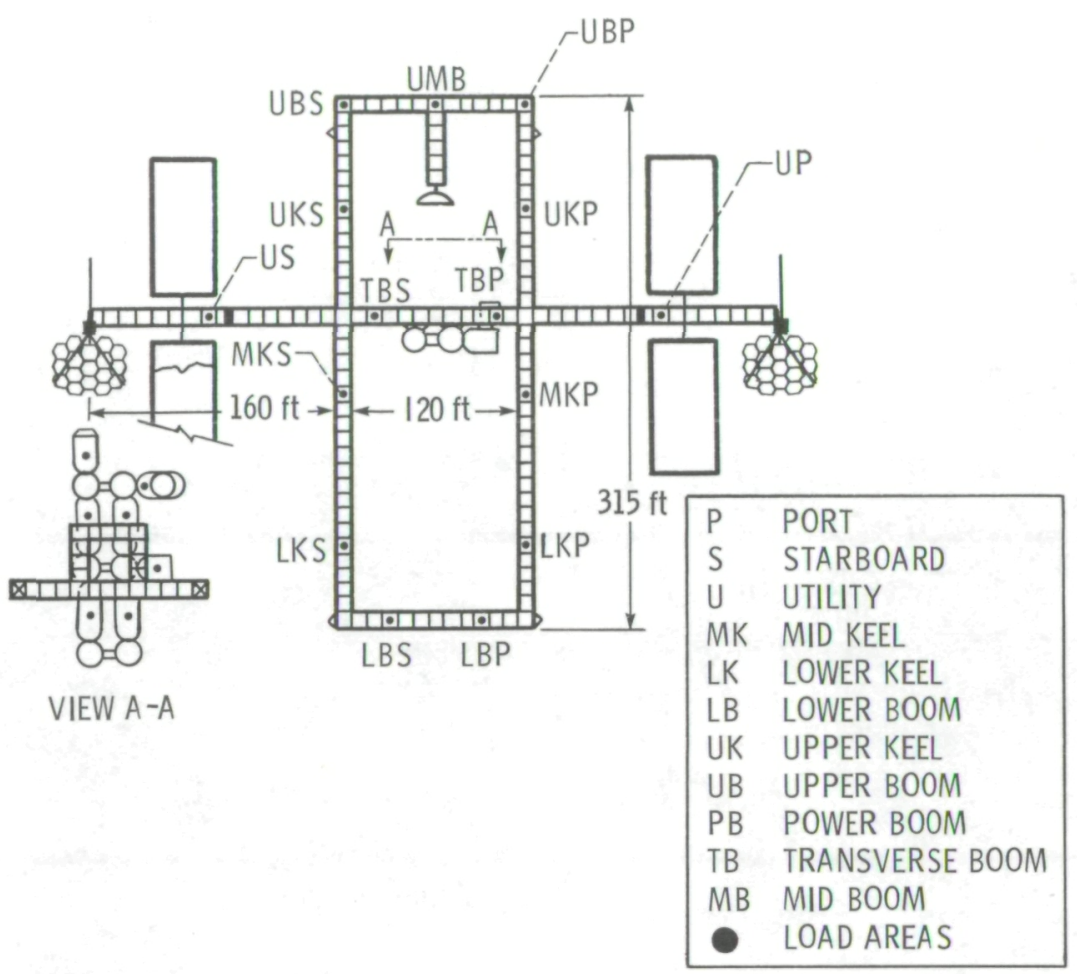

Figure 1. - Basic space station layout. All dimensions are approximate.

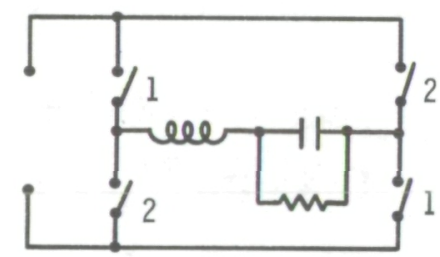

SWITCHED FULL BRIDGE

RESONANT LOAD

(LOW IMPEDANCE) OUTPUT

RESONANT CONVERTER

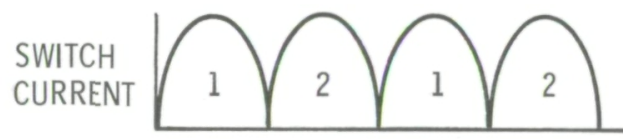

CURRENTS ARE HALF SINUSOIDS

LOAD

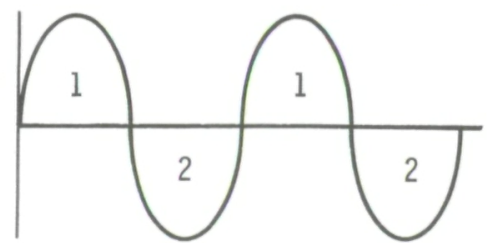

ALL SWITCHING AT ZERO CURRENT

- NO FREOUENCY DEPENDENT SWITCH LOSS

- NO SECOND BREAKDOWN

Figure 2. - Parallel resonant conversion (MAPHAM). 
ACTUAL CIRCUIT CONSIDERATIONS

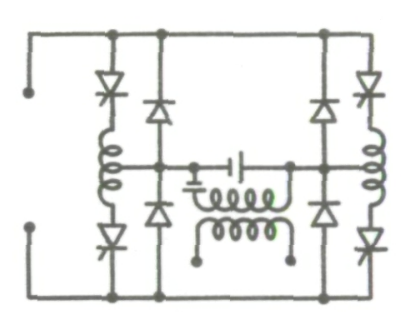

- CURRENT TRIGGER FREQUENCY, $20 \mathrm{kHz}$

- CIRCUIT RESONANT FREQUENCY, $28 \mathrm{kHz}$

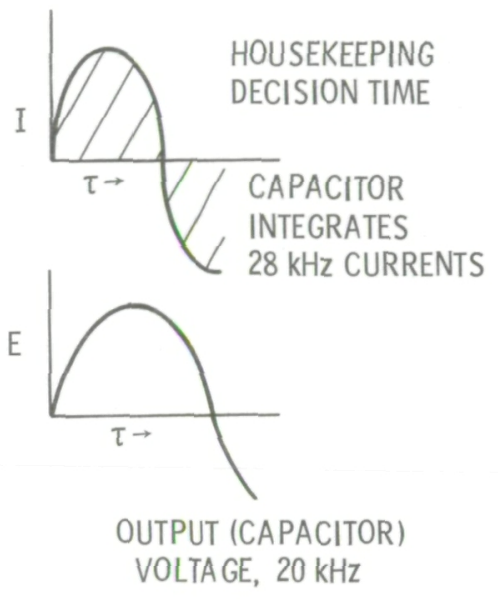

Figure 3. - Waveforms at resonant capacitor.
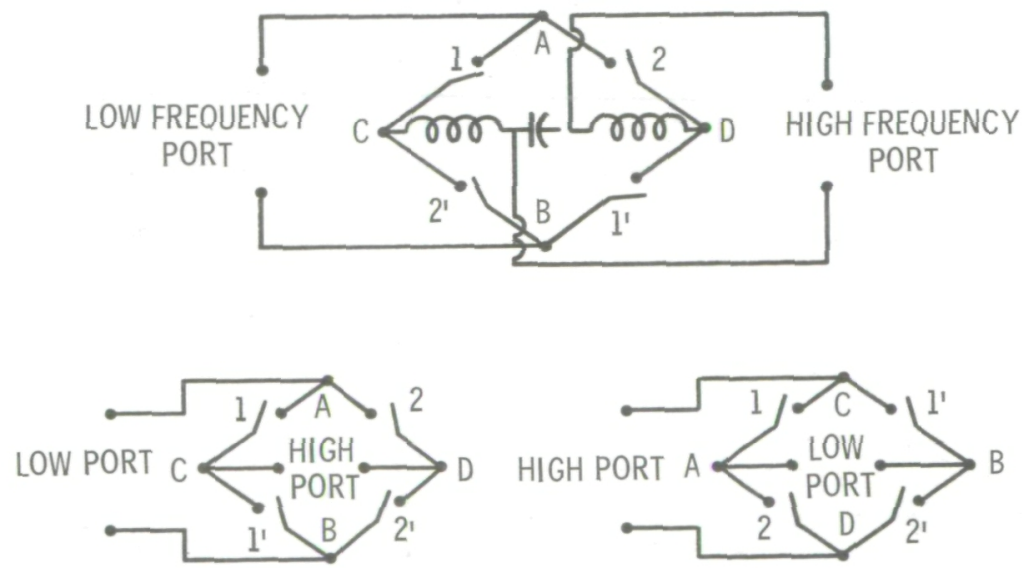

RESONANT BRIDGE WILL PASS ENERGY BETWEEN LOW FREQUENCY PORT AND HIGH FREQUENCY PORT BI-DIRECTIONALLY

Figure 4. - Circuit symmetry. 


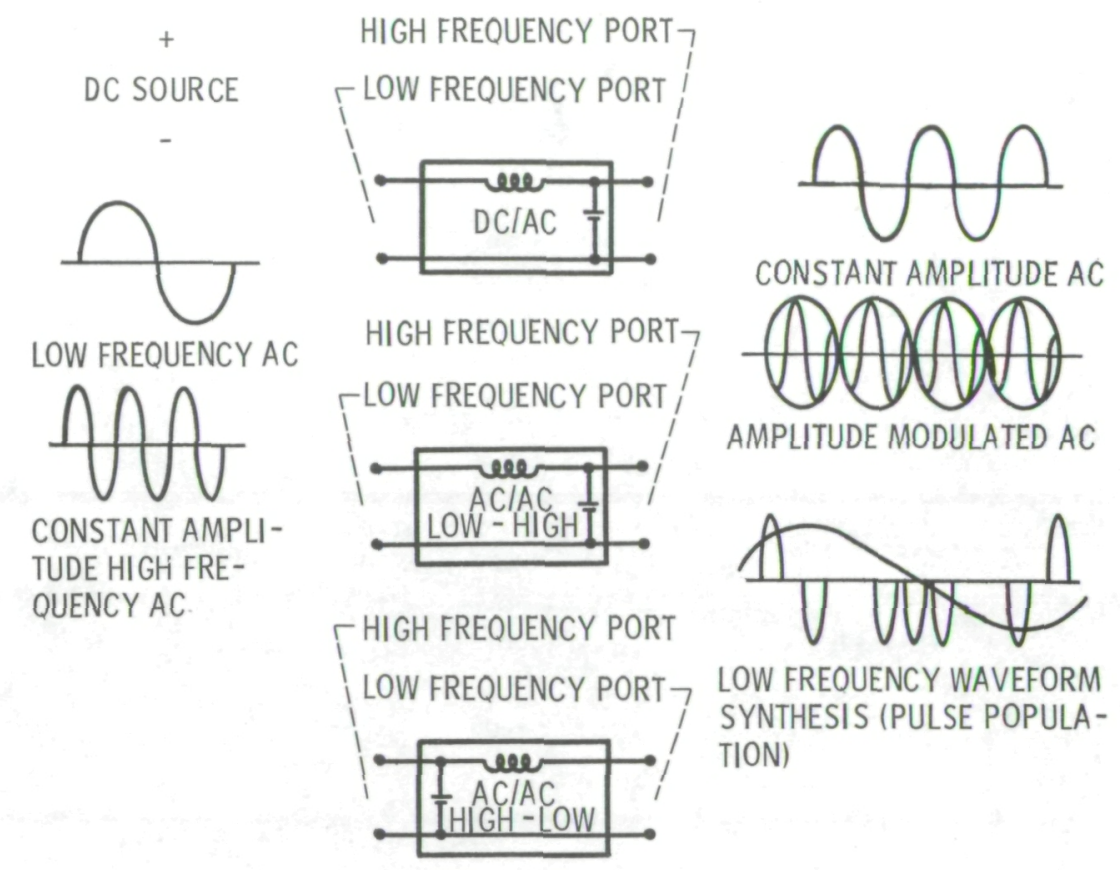

Figure 5. - Resonant circuit transfer waveforms.

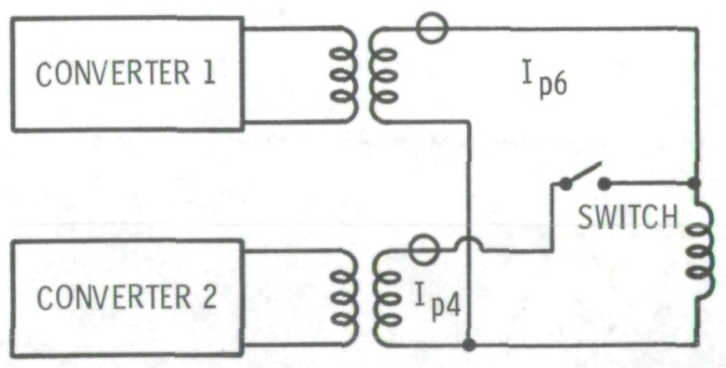

TEST CIRCUIT

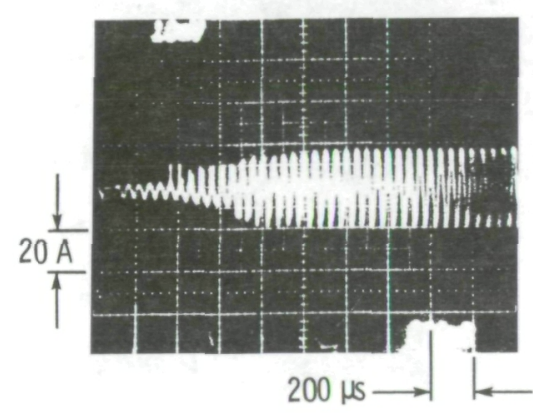

I 4 , TRANSIENT RESPONSE

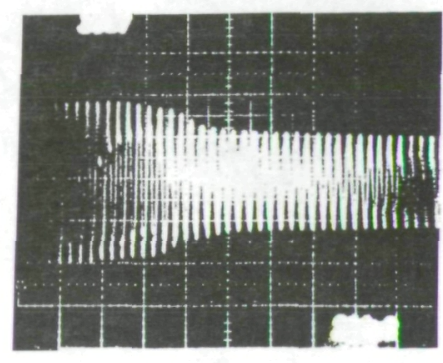

$I_{p 6}$, TRANSIENT RESPONSE

Figure 6. - Step paralleled converters. (General Dynamics) 
TO CHANGE DC VOLTAGE LEVELS (DC/DC CONVERTER)

\section{DC/AC/DC}
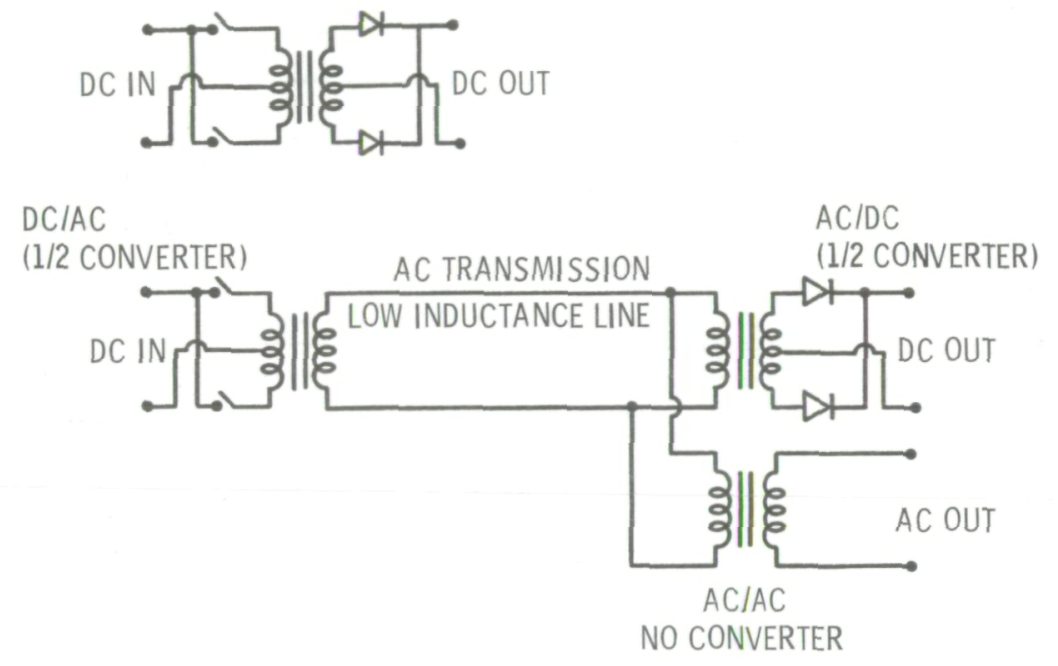

Figure 7. - "Split" system concept.

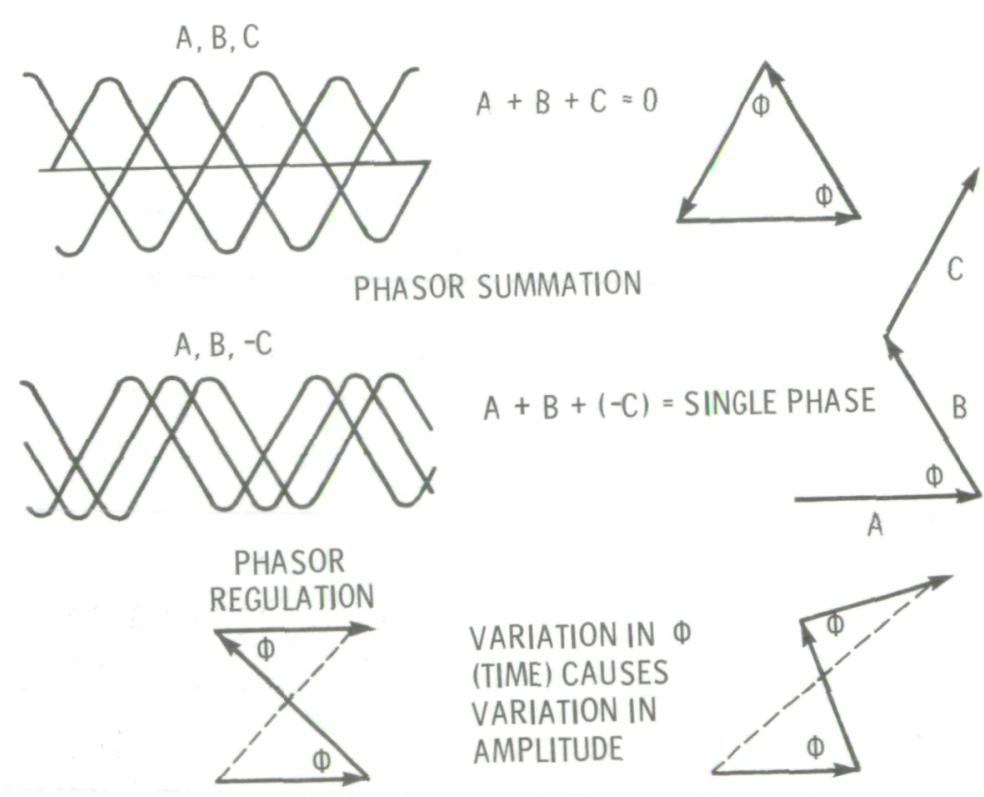

Figure 8. - Basic concepts. 
ANY TWO OR MORE SYNCHRONOUS

PHASORS MAY BE TIME DELAYED

TO PROVIDE REGULATION

- SIX UNITS MAY BE CONNECTED

TO PROVIDE PHASE BY PHASE

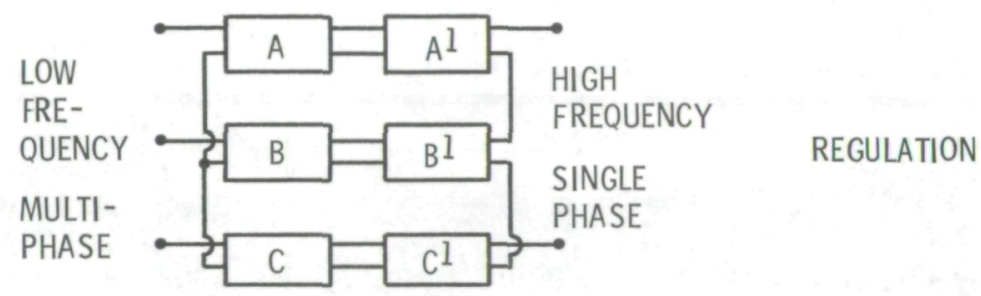

- input converters (A, B, C) Remain balanced (120 Phase Relation)

- OUTPUt CONVERTERS ARE PHASED FOR REGULATION

Figure 9. - Phase by phase regulation.

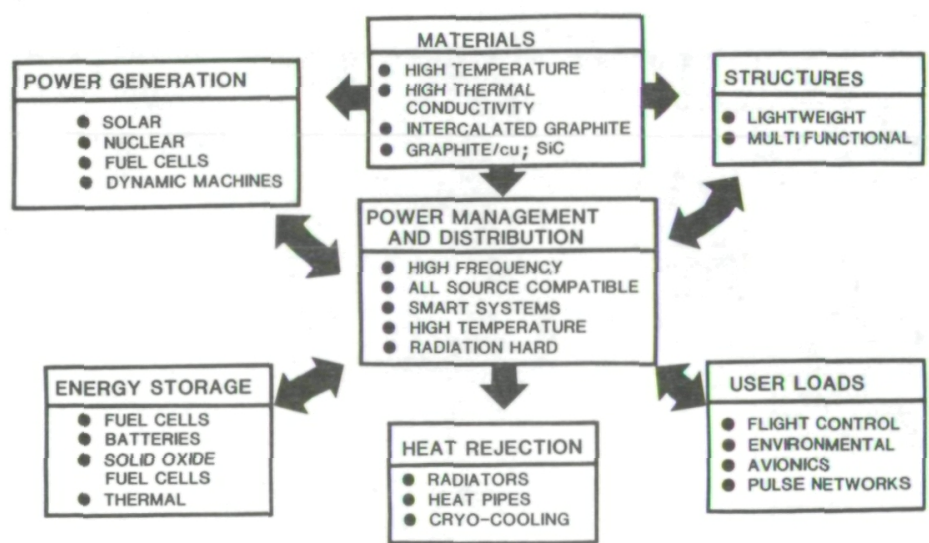

Figure 10. - LeRC program for mass limited missions. 


\begin{tabular}{|c|c|c|c|}
\hline $\begin{array}{l}\text { 1. Report No. } \\
\text { NASA TM-87314 }\end{array}$ & 2. Government Accession No. & \multicolumn{2}{|c|}{ 3. Recipient's Catalog No. } \\
\hline \multicolumn{2}{|c|}{$\begin{array}{l}\text { 4. Title and Subtitle } \\
\text { Space Station } 20-\mathrm{kHz} \text { Power Management and } \\
\text { Distribution System }\end{array}$} & \multicolumn{2}{|c|}{$\begin{array}{l}\text { 6. Performing Organization Code } \\
506-41-4 A\end{array}$} \\
\hline \multirow{2}{*}{\multicolumn{2}{|c|}{$\begin{array}{l}\text { 7. Author(s) } \\
\text { Irving G. Hansen and Gale R. Sundberg }\end{array}$}} & \multicolumn{2}{|c|}{$\begin{array}{l}\text { 8. Performing Organization Report No } \\
\text { E-3045 }\end{array}$} \\
\hline & & \multicolumn{2}{|l|}{ 10. Work Unit No. } \\
\hline \multicolumn{2}{|c|}{$\begin{array}{l}\text { 9. Performing Organization Name and Address } \\
\text { National Aeronautics and Space Administration } \\
\text { Lewis Research Center } \\
\text { Cleveland, Ohio } 44135\end{array}$} & \multicolumn{2}{|c|}{\begin{tabular}{|l}
11. Contract or Grant No. \\
\end{tabular}} \\
\hline \multicolumn{2}{|c|}{$\begin{array}{l}\text { 12. Sponsoring Agency Name and Address } \\
\text { National Aeronautics and Space Administration } \\
\text { Washington, D.C. } 20546\end{array}$} & \multicolumn{2}{|c|}{ 14. Sponsoring Agency Code } \\
\hline \multicolumn{4}{|c|}{$\begin{array}{l}\text { Prepared for the } 1986 \text { Power Electronics Specialists Conference, sponsored by the } \\
\text { Institute of Electrical and Electronics Engineers, Vancouver, Canada, June 23-27, } \\
1986 \text {. }\end{array}$} \\
\hline \multicolumn{4}{|c|}{$\begin{array}{l}\text { During the conceptual design phase a } 20-\mathrm{kHz} \text { power distribution system was } \\
\text { selected as the reference for the space station. The system is single-phase } 400 \\
\text { VRMS, with a sinusoidal wave form. The initial user power level will be } 75 \mathrm{~kW} \\
\text { with growth to } 300 \mathrm{~kW} \text {. The high-frequency system selection was based upon } \\
\text { considerations of efficiency, weight, safety, ease of control, interface with } \\
\text { computers, and ease of paralieling for growth. Each of these aspects will be } \\
\text { discussed as well as the associated trade-offs involved. An advanced } \\
\text { development program has been instituted to accelerate the maturation of the } \\
\text { high-frequency system. Some technical aspects of the advanced development } \\
\text { program will be discussed. }\end{array}$} \\
\hline $\begin{array}{l}\text { 17. Key Words (Suggested by Author(s)) } \\
\text { Power system } \\
\text { Resonant conversion }\end{array}$ & $\begin{array}{r}\text { 18. Distrib } \\
\text { Unc } \\
\text { STAl }\end{array}$ & ry 20 & \\
\hline $\begin{array}{l}\text { 19. Security Classif. (of this report) } \\
\text { Unc lass if ied }\end{array}$ & $\begin{array}{l}\text { 0. Security Classif. (of this page) } \\
\text { Unc lass if ied }\end{array}$ & 21. No. of pages & 22. Price $^{*}$ \\
\hline
\end{tabular}

${ }^{\star}$ For sale by the National Technical Information Service, Springfield, Virginia 22161 
N/NS 